\title{
Psychosocial effects of competitive Boccia program in persons with severe chronic disability
}

\author{
Sharon Barak, PhD; ${ }^{*}$ Nuria Mendoza-Laiz, PhD; ${ }^{2}$ Maria Teresa Gutiérrez Fuentes, PhD; ${ }^{3}$ Maria Rubiera, \\ PhD; ${ }^{3}$ Yeshayahu Hutzler, $\mathbf{P h D}^{4}$ \\ ${ }^{1}$ The Edmond and Lily Safra Children's Hospital, Chaim Sheba Medical Center, Ramat Gan, Israel; and Kaye \\ Academic College of Education, Beer-Sheba, Israel; ${ }^{2}$ Facultad de Ciencias del Deporte, Universidad de Castilla La \\ Mancha, Toledo, Spain; ${ }^{3}$ CRE de Discapacidad y Dependencia, IMSERSO, León, Spain; ${ }^{4}$ Zinman College of Physical \\ Education and Sport Sciences and Israel Sport Center for the Disabled, Israel
}

\begin{abstract}
People with severe physical disabilities may experience psychosocial problems. Boccia is one sport that athletes with severe disability can engage in, but no information on the effects of Boccia on psychosocial outcomes for participants with severe disability is available. Therefore, we analyzed the effects of Boccia on psychosocial outcomes in persons with severe disabilities. The study included two competitive Boccia groups: independent competitive (IC) $(n=9)$ and nonindependent competitive (NIC) $(n=7)$, as well as a recreational Boccia group $(n=14)$ and control subjects $(n=13)$ (mean age for all participants $=46.46+/-$ $10.75 \mathrm{yr}$ ). All participants underwent a rehabilitation program. Between-group differences in change scores were assessed using analysis of variance/multivariate analysis of variance. Withingroup differences were compared using $t$-tests and effect sizes (ESs). Change in psychosocial parameters was not significantly influenced by study group $(p>0.05)$. All groups presented moderate-to-large ESs in physical and psychological quality of life (ES > 0.51 ). In comparison to the control group, who presented small-totrivial ESs in General Health Questionnaire-28 (GHQ-28), StateTrait Anxiety Inventory, and Profile of Mood States-Tension, the IC and recreational group presented moderate ESs in GHQ-28, whereas the NIC group presented moderate ESs in anxiety and tension. In conclusion, the rehabilitation program had a general positive effect on the psychosocial status of individuals with severe physical disabilities. However, the competitive Boccia groups demonstrated a greater number of favorable changes, suggesting an added value of participation in Boccia.
\end{abstract}

Key words: Boccia, cerebral palsy, exercise, physical activity, physical disability, physical training, psychological adaptation, quality of life, rehabilitation, self-efficacy, severe physical disability, sports.

\section{INTRODUCTION}

Competitive (i.e., Paralympic) sports have been reported to induce a number of psychosocial effects in persons with a disability [1] (e.g., increased self-esteem, well-being, and quality of life and reduced anxiety and depression) [2-8]. However, these outcomes were almost exclusively attributed to athletes with limitations that enabled them to independently cope with most daily tasks, such as those with paraplegia or lower-limb amputation. In contrast, some authors discuss the specific difficulties of individuals with severe disabilities (e.g., transportation, dependence on others for performing sports and daily tasks, psychosocial vulnerability) and recommend accounting for these unique circumstances [9-11]. So far, very few (if any) studies have identified

Abbreviations: $\mathrm{ANOVA}=$ analysis of variance, $\mathrm{BI}=$ Barthel Index, $\mathrm{CP}=$ cerebral palsy, ES = effect size, GHQ-28 = General Health Questionnaire-28, IC = independent competitive, MANOVA $=$ multivariate analysis of variance, $\mathrm{NIC}=$ nonindependent competitive, POMS = Profile of Mood States, SRC = State Referral Center, STAI = State-Trait Anxiety Inventory, WHOQOL $=$ World Health Organization Quality of Life.

*Address all correspondence to Sharon Barak, PhD; Department of Pediatric Rehabilitation, Chaim Sheba Medical Center, Tel Hashomer 5265601, Israel; +972507755657; fax: +97235302045. Email: sharoni.baraki@gmail.com http://dx.doi.org/10.1682/JRRD.2015.08.0156 
sports or other interventions that may help adults with severe physical disability improve their psychosocial functioning.

One of the most popular competitive sport activities for athletes with a severe disability is Boccia. It is also the most established and, with the exception of power soccer appearing in recent years [12-14], the only group game activity available for persons with severe disability in most countries. Boccia can be played by athletes with neuromuscular disorders that severely affect the motor system, such as muscular dystrophy, Friedrich ataxia, and multiple sclerosis [15]. The classification system comprises four categories: $\mathrm{BC} 1$ - athletes with cerebral palsy (CP) who have restricted trunk movement and poor sitting balance but are able to throw the ball, usually overhand; $\mathrm{BC} 2$-athletes with $\mathrm{CP}$ who have greater sitting balance than $\mathrm{BC} 1$ athletes and are usually able to pick the ball up from the floor and throw either overhand or underhand; $\mathrm{BC} 3$ - athletes with $\mathrm{CP}$ who are unable to hold and release a ball and therefore may use a ramp and an assistant; and $\mathrm{BC} 4$ - athletes who have a severe physical disability with a diagnosis other than $\mathrm{CP}$, such as progressive muscular dystrophy [16].

In Boccia, a target ball, "the Jack," is thrown by one participant and then this player and his or her opponent alternately throw balls in order to bring their own balls closer to the target. Therefore, the game requires technical function, accuracy, strategic planning, and mental toughness. Moreover, the Boccia activity requires fitness components such as upper-body strength, dynamic stability, perceptual-motor awareness, and visual-motor coordination, which are important not only for sports but also for daily functioning. The specific throwing technique in Boccia is unique to each player because of his or her specific capacities and limitations. However, scientific investigations reported that participants with spasticity prefer the underhand technique [16] and that the only significant difference found in a selected sample of Spanish participants between classifications $\mathrm{BC} 1$ and $\mathrm{BC} 2$ was the electromechanical delay that was larger in the $\mathrm{BC} 1$ players [17].

In spite of its $30 \mathrm{yr}$ playing history, very little research has reported scientific evidence related to Boccia athletes. Most studies focus on the technical, biomechanical, and learning aspects of Boccia throwing [1821]. Only one study has reported on motivational attributes of Paralympic athletes that included Boccia participants [22]. The unique technical and tactical perspectives of Boccia, including comprehensive learning processes and social exchange, may provide unique and added value to the psychosocial benefits of participation in this activity. Nevertheless, no information has been reported thus far on the effect of participation in Boccia on mood, quality of life, anxiety, well-being, and self-esteem of participants with severe disability.

Therefore, because of the potential psychosocial effects of participation in Boccia and the lack of evidence regarding it, this study analyzed the effects of a competitive Boccia training program on quality of life, selfesteem, anxiety, and mood states compared to a recreational Boccia training program and no specific physical activity training in residents of a comprehensive rehabilitation center for persons with severe chronic disabilities.

\section{METHODS}

\section{Participants}

All participants gave their informed consent to participate in this study. Participants were residents at a Spanish State Referral Center (SRC) for persons with severe disability. Participants were admitted to the rehabilitation center based on their level of disability and psychosocial characteristics. More specifically, individuals admitted to the center are not independent in their activities of daily living and do not have the economical and familial resources to live independently. Study participants either lived permanently or temporarily $(12-18 \mathrm{mo})$ in the SRC center.

Four cohorts were created - two competitive Boccia groups: independent competitive (IC, $n=9)$ and nonindependent competitive (NIC, $n=7$ ), recreational Boccia $(n=14)$, and control $(n=13)$. Control subjects did not participate in any leisure-time physical activity. The competitive players included three $\mathrm{BC} 1$ and six $\mathrm{BC} 2$ players in the IC group and seven $\mathrm{BC} 3$ players in the NIC group. Participants in the IC group played Boccia without the aid of an assistant. Participants in the NIC group played Boccia with the aid of an assistant. Participants in the recreational group did not play Boccia on a regular basis. However, they occasionally played Boccia in their leisure time (i.e., Boccia as a leisure-time activity).

Criteria for inclusion in this study were (1) disability involving all four limbs to at least a moderate extent (i.e., a person who requires assistance in order to conduct activities of daily living), (2) functional ambulation with manual or power wheelchair, and (3) the ability to follow 
instructions and to complete questionnaires with or without assistance. Exclusion criteria were any recent (last 2 mo) severe changes in medical condition (e.g., surgery).

\section{Outcome Measures}

Outcome measures consisted of demographic information and activity limitations. Demographic information was obtained from study participant and/or family member interviews. Activity limitations were assessed using the Barthel Index (BI). More specifically, the BI was used to establish participants' ability to independently ambulate and conduct activities of daily living upon entry to the program (pretest). Each item is rated based on the amount of assistance required to complete it [23]. The BI yields a total score out of 100. Higher scores denote a greater degree of functional independence [24].

We also evaluated a total of five psychological domains: mood states (Profile of Mood States [POMS], anxiety (State-Trait Anxiety Inventory [STAI]), quality of life (World Health Organization Quality of Life-BREF assessment [WHOQOL-BREF]), self-esteem (Rosenberg Self-Esteem), and mental health problems (General Health Questionnaire-28 [GHQ-28]). The aforementioned psychological domains were selected as they provide information regarding the participant's well-being [5]. It is important to evaluate the well-being of individuals with disability because they commonly experience symptoms of psychological distress [25]. In addition, it has been reported that sports participation can positively affect the well-being of individuals with disability [5]. All the selected outcome measures have sound psychometric properties. Following is a description of the various psychological outcome measures used.

\section{Profile of Mood States}

The POMS is a standardized and validated 65 -item inventory [26-27] that assesses six dimensions of transient mood states: Anger, Confusion, Depression, Fatigue, Tension, and Vigor. Each item is rated on a 5-point Likert scale ranging from 0 (not at all) to 4 (extremely). The raw score in each dimension is $<60$. Total mood disturbance can also be calculated by subtracting the Vigor subscale score from the sum of the Tension, Depression, Anger, Fatigue, and Confusion subscale scores. Total scores can range from 0 to 200, with lower scores indicative of people with more stable mood profiles [26]. In the current study, the six subscales and total scores for the POMS were established both pre- and posttest. POMS was used to measure mood states because previous POMS-related studies demonstrated superior outcomes of highly active athletes compared with those with a medium or low level of physical activity [28-31].

\section{State-Trait Anxiety Inventory}

The STAI is a self-report questionnaire that assesses current anxiety symptoms and a generalized inclination to be anxious. The questionnaire is composed of two subscales: Anxiety-State and Anxiety-Trait. The first establishes the current state of anxiety, whereas the latter establishes relatively stable aspects of anxiety proneness [32-34]. In both the Anxiety-State and Anxiety-Trait, the range of scores is from 20 to 80, with higher scores indicating a greater level of anxiety. In the Anxiety-State, scores of 39 to 40 have been suggested as a cutoff point for clinically significant symptoms [35-36]. In the current study, we administered the Anxiety-State at both preand posttests, whereas we administered the Anxiety-Trait at pretest only. The Anxiety-Trait was used only in pretest because it measures "proneness" to anxiety as a characteristic (i.e., a long-standing trait). Therefore, this subscale is less responsive to change than the AnxietyState [37]. We assessed anxiety because exercise can be used as a technique for improving state anxiety.

\section{World Health Organization Quality of Life-BREF}

The WHOQOL-100 quality of life assessment was developed by the WHOQOL Group. The WHOQOL-100 allows detailed assessment of quality of life. However, the WHOQOL-100 may be too lengthy for practical use (e.g., time restrictions and respondent burden). The WHOQOLBREF has been developed to provide a shorter version to assess quality of life. The instrument consists of only 26 items, but in order to comprehensively assess quality of life, 1 item from each of the 24 domains of the WHOQOL100 has been included. Moreover, two items from the Overall Quality of Life and General Health facet have been included [38]. Analyses of internal consistency, item:total correlations, and discriminant and construct validity indicate that the WHOQOL-BREF has good-toexcellent psychometric properties of reliability and performs well in preliminary tests of validity. In addition, the WHOQOL-BREF has been cross-culturally validated [39]. As the WHOQOL-BREF is a comprehensive quality of life assessment questionnaire that aids in reducing respondent burden and has robust psychometric properties, it has been used in this study to assess quality of life. The WHOQOL-BREF measures the following domains: Physical 
Health, Psychological Health, Social Relationships, and Environment, and General. In the Physical Health, Psychological Health, Social Relations, and Environmental domains, the raw scores range from 0 to 35,0 to 30,0 to 15 , and 0 to 40 , respectively [38].

\section{Rosenberg Self-Esteem}

The Rosenberg Self-Esteem is a 10-item scale that measures individual self-esteem by establishing both negative and positive feelings about the self [40-41]. Participants read statements such as "I feel that I am a person of worth, at least on an equal basis with others," and rate their statement on a 4-point Likert scale, ranging from strongly agree to strongly disagree [40]. Scores range from 10 to 40, with lower scores indicating lower self-esteem. The Rosenberg Self-Esteem questionnaire was administered twice, at pre- and posttest. Self-esteem was assessed because it is important for a satisfying and successful life. In addition, self-esteem is a cardinal aspect of psychological well-being [40]. Moreover, physical activity is an important component of positive self-esteem [42].

\section{General Health Questionnaire-28}

The GHQ-28 [43] is a mental well-being assessment [44-46]. The GHQ-28 questionnaire measures the common mental health problems of Anxiety, Depression, Social Withdrawal, and Somatic Symptoms. Participants read statements such as "Have you been getting scared or panicky for no good reason?" and rate the statement on a 4-point Likert scale, ranging from "not at all" to "much more than usual." The total possible score ranges from 0 to 28 (higher scores indicate a greater probability of psychiatric distress) and allows for means to be calculated both for the global total as well as for the four subscales [45]. In the current study, the global total score was established twice: at pre- and posttest. The GHQ-28 was selected to assess mental well-being because it is widely used in screening minor psychiatric disorders in the community. In addition, it has been reported that mental health status, as evaluated by the GHQ-28, improved after participation in a physical activity program [47].

Most participants' fine motor control was poor, and they were not able to independently complete the study questionnaires. The decision regarding assistance for participants to complete the questionnaire was established by occupational therapists using a series of fine motor control tests. Moreover, the internal consistency of all the aforementioned outcome measures was examined via
Cronbach alpha. The analyses showed that all outcome measures had acceptable Cronbach alpha $(\alpha>0.70)$ in both pre- and posttests.

\section{Procedures}

This is a pre-post research study. Administration of all questionnaires was performed twice by qualified personnel of the SRC, which included two certified psychologists and a certified occupational therapist.

\section{Intervention}

All cohorts were followed for a period of 4 mo between pre- and posttests. Competitive Boccia participants (both IC and NIC) trained 3 times per week for $1.5 \mathrm{~h}$ sessions each time. The decision on training volume and intensity was made by consultation with a team that included a Boccia coach, fitness instructors, physiotherapy and occupational therapy practitioners, and a psychologist. The training included throwing balls to different targets, technical and tactical drills, as well as participation in training and competition games. In addition, these players participated in a repetitive strength training program twice a week for $1 \mathrm{~h}$ each session in a group setting. Recreational participants were included in the training that emphasized tactics 2 sessions per week but not in the games and not in one specific training schedule.

All study participants underwent an individualized rehabilitation program. Rehabilitation is multidisciplinary and may consist of physical therapy (two $30 \mathrm{~min}$ weekly sessions), occupational therapy (two $1 \mathrm{~h}$ weekly sessions), speech and language rehabilitation, psychological therapy, and therapeutic exercise. The purpose of the rehabilitation program is to slow the resident's rate of deterioration in function, maintain their function, or improve the functional level. Competitive Boccia is not part of the rehabilitation program. However, recreational Boccia is an integral part of the rehabilitation program. Not all of the center's residents choose to partake in recreational Boccia. Moreover, not all residents engage in therapeutic exercise. Some residents choose to partake in different forms of rehabilitative activities

\section{Statistical Analysis}

Data were processed and analyzed using SPSS, version 15 (IBM; Armonk, New York). The independent variable in this study was treatment group (IC, NIC, recreational, and control). Dependent variables consisted of five different 
outcome measures: POMS (six subscales and total), STAI (two subscales, with only one subscale with both pre- and posttest measurements), GHQ-28 (one score), WHOQOLBREF (five subscales), and Rosenberg Self-Esteem (one score). Change scores (posttest-pretest) were calculated for all the dependent variables. In order to determine whether a covariate model was needed in the between-group analysis, we calculated correlations between change scores and potential covariates, namely age and BI. The results indicated small $(r<0.30)$ and nonsignificant correlations. Moreover, in all the dependent outcome measures, except for POMS-Fatigue, no between-groups differences in pretest were observed. Therefore, we decided not to use a statistical model with covariates (i.e., analysis of covariance or multivariate analysis of covariance). Accordingly, betweengroup differences in dependent variables with one scale (i.e., STAI, GHQ-28, and Rosenberg Self-Esteem) were analyzed using one-way analysis of variance (ANOVA), whereas dependent variables with more than one scale (i.e., POMS and WHOQOL-BREF) were analyzed using a oneway multivariate analysis of variance (MANOVA). Pairwise comparisons were conducted only in models with significant overall ANOVA effect $(p<0.05)$. Pairwise comparisons were calculated using Tukey Student-NewmanKeuls procedure.

Mean within-group differences across pre- and posttests in psychosocial variables were compared using a dependent samples $t$-test. In this procedure, the significance level for the STAI Anxiety-Trait, STAI AnxietyState, Rosenberg Self-Esteem, and GHQ-28 scales was set at 0.05. In WHOQOL-BREF, the level of significance was set at 0.05 and adjusted to $0.01(0.05 / 5)$ using the Bonferroni procedure. In POMS, the level of significance was adjusted to 0.007. In addition, if the assumption of homogeneity of variance was violated, a correction for the unequal variance was conducted using the Welch test [48].

The power of a study is confounded, among other things, by sample size. As the sample size in this study was relatively small, it might have had a negative effect on the study's power; a nonsignificant $p$-value will not necessarily indicate a trivial result. Because our sample size was small and may have been accountable for null results $(p>0.05)$, we also report the effect sizes (ESs). One of the advantages of the ES is that it is independent of certain details of the experiment, such as sample size. In order to calculate the ES, we used Cohen $d$ (mean $\Delta /$ stan-

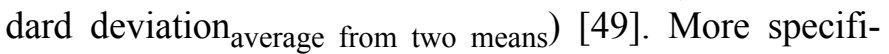
cally, each group's pretest baseline values were used. For within-subjects tests, a correction for the dependence among means was conducted using the correlations between the two means following the Morris and DeShon equation [50]. In general, values $\leq 0.20$ are considered trivial ESs, values $0.21-0.50$ as small ESs, values $0.51-$ 0.80 as moderate ESs, and values $>0.80$ as large ESs [49].

\section{RESULTS}

Participants' mean age ranged from $41.57 \pm 12.10 \mathrm{yr}$ (in the NIC group) to $48.84 \pm 9.95 \mathrm{yr}$ (in the control group). The mean age of the entire group mean was $46.46 \pm 10.75$ yr. Participants' disability etiologies consisted of $\mathrm{CP}$, multiple sclerosis, traumatic brain injury, and Friedreich ataxia. In the IC group, most participants $(n=6)$ used manual wheelchairs. In the NIC group, three participants used manual wheelchairs and four used power wheelchairs. In the recreational Boccia and control groups, all participants used power wheelchairs. In addition, in comparison to participants in the IC and the recreational groups, participants in the NIC group had significantly lower BI scores (Table 1).

\section{Between-Group Differences in Psychosocial Parameters}

A one-way ANOVA and MANOVA were calculated in order to examine the effect of training (IC, NIC, recreational, and control) on change scores of psychosocial variables with one and multiple levels, respectively. Both ANOVA and MANOVA revealed that change in psychosocial parameters was not significantly influenced by the study group ( $p \geq 0.05$ ) (Figures 1-3).

\section{Within-Group Changes from Pre- to Posttest}

The four activity groups improved from pre- to posttest in WHOQOL-BREF Physical. In addition, the control group also presented improvements in WHOQOL-BREF Psychological, whereas the NIC group presented improvements on the Rosenberg Self-Esteem (Table 2). It is important to note that in both Table 2 and Figures 1-3, the within-group variability in the various study groups appears to be large.

\section{Effect Sizes}

ESs of the various parameters differed widely. All four groups demonstrated large ESs ( $E S \geq 0.80$ ) in WHOQOLBREF Physical and at least moderate ESs (ES $=0.51-$ 0.80) in WHOQOL-BREF Psychological. The IC group 
JRRD, Volume 53, Number 6, 2016

Table 1.

Demographic and clinical features of study sample.

\begin{tabular}{|c|c|c|c|c|}
\hline Variables & IC $(n=9)$ & NIC $(n=7)$ & Recreational $(n=14)$ & Control $(n=13)$ \\
\hline$\overline{\text { Age }(y r), \text { mean (SD) }}$ & $43.22(13.80)$ & $41.57(12.10)$ & $48.78(7.96)$ & $48.84(9.95)$ \\
\hline \multicolumn{5}{|l|}{ Sex, No. } \\
\hline Male & 3 & 5 & 7 & 5 \\
\hline Female & 6 & 2 & 7 & 8 \\
\hline \multicolumn{5}{|l|}{ Disability Type, No. } \\
\hline Cerebral Palsy & 6 & 6 & 6 & 5 \\
\hline Friedreich Ataxia & 3 & 0 & 3 & 1 \\
\hline Barthel Index, mean (SD) & $63.33(25.86)^{*}$ & $19.28(13.04)^{\dagger}$ & $66.78(26.10)^{*}$ & $47.69(34.61)$ \\
\hline \multicolumn{5}{|c|}{$\begin{array}{l}\text { *Significantly different than NIC (two-tailed, } p<0.05 \text { ). } \\
\text { †Significantly different than IC and recreational groun (both two }\end{array}$} \\
\hline $\begin{array}{l}\text { †Significantly different than IC at } \\
\text { IC = independent competitive, N }\end{array}$ & onal group (both ty & $0.05)$. & tion & \\
\hline
\end{tabular}

also presented moderate ESs in WHOQOL-BREF General $(\mathrm{ES}=0.516)$ and GHQ-28 (ES $=-0.551)$. The NIC group also presented moderate-to-large ESs in POMS Tension $(\mathrm{ES}=-0.578)$, STAI Anxiety-State ( $\mathrm{ES}=-0.686)$, WHOQOL-BREF General (ES = 1.226), and Rosenberg SelfEsteem $(E S=0.713)$. The recreational and control groups only presented additional favorable ESs in GHQ-28 and WHOQOL-BREF General, respectively. In all groups, a few negative moderate-to-large ESs were also observed (IC group: POMS Vigor and Rosenberg Self-Esteem; and control group: Rosenberg Self-Esteem). Table 3 gives a detailed description of ES analysis.

In summary, all the study groups demonstrated moderate-to-large changes in the psychosocial parameters. However, the IC and the NIC groups demonstrated at least moderate favorable ESs in 4 (IC) and 6 (NIC) out of the 15 variables evaluated, respectively, whereas the recreational and the control groups presented at least moderate favorable ESs in 3 variables (Table 3).

\section{DISCUSSION}

The present study followed a variety of psychosocial variables during the process of rehabilitation in cohorts of chronically and severely disabled individuals who engaged in sports at different intensity levels. Very few studies have followed sport practitioners during a rehabilitation process, and very few studies were encountered that addressed the psychosocial effect of sport participation on persons with a severe disability.
Generally, the outcomes of the current study revealed a positive psychosocial effect of the comprehensive rehabilitation program; improvements in the psychosocial parameters were also observed in the control group. In addition to the therapeutic program effects, the specific effect of the competitive program (IC and NIC groups) compared with the recreational group and non-Boccia group (control) was noticeable. More specifically, in comparison to the recreational and control groups, the IC and NIC groups presented a moderate favorable ES in more outcome measures. The discussion that follows will refer to the general effect first and then to the specific effects in each of the scales measured.

Surprisingly, the recreational group apparently gained less from the additional sport activity than the control group. It may be speculated that those residents who did not participate in sport activities had other psychosocially challenging interests and did not find the leisure sport participation attractive and necessary, as their interests were fulfilled otherwise. Also, since the competitive groups represented the center in national and international competitions, it may be that those who were included in the recreational group suffered from feelings of inferiority regarding the additional attention that the competitive groups allegedly received from coaches and other administrators. However, based on the fact that the competitive groups, including the NIC, gained large ESs on more variables than those who did not practice sport, it may be suggested that participation in a rigorous sport activity is positively related to psychosocial function. 


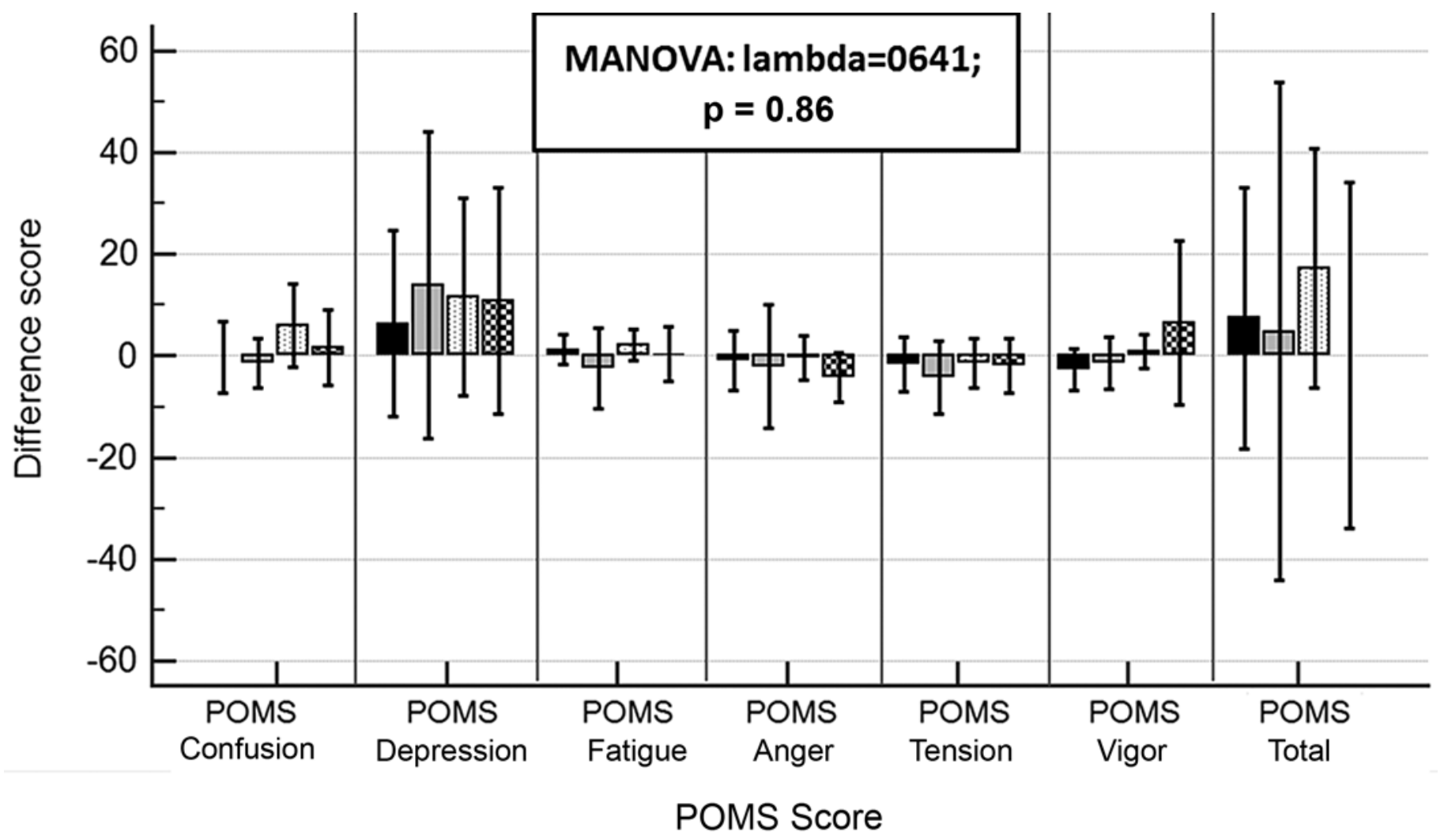

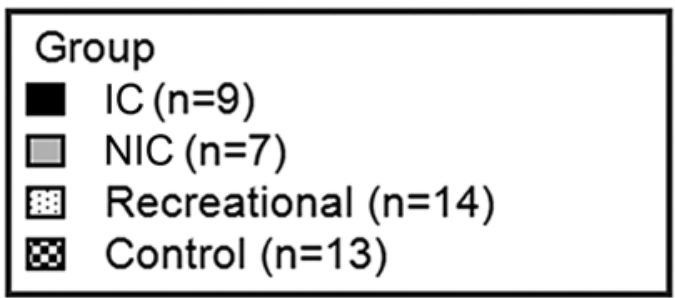

Figure 1.

Profile of Mood States (POMS) score difference. Mean change was calculated as posttest-pretest. Vertical line extends from the minimum to the maximum value. IC = independent competitive, MANOVA = multivariate analysis of variance, NIC = nonindependent competitive.

\section{Profile of Mood States}

Previous POMS-related studies demonstrated superior outcomes for athletes compared with controls and for highly active athletes compared with those with a medium or low level of physical activity [28-31]. For instance, Martin et al. reported that in comparison to Paralympic women basketball players who did not make the U.S. team, players who made it to the U.S. basketball team scored higher in vigor and lower in depressed mood [31]. In contrast, in the current study, no between-group significant differences were observed in POMS change scores (Figure 1). Differences between the studies' results may be related to the participants' disability level and sports type. In the current study, participants had relatively severe disability (involving all four limbs), whereas in Martin et al.'s study [31], participants with lower-limb disabilities (e.g., knee dysfunction) only were included. In addition, the physical demands of wheelchair sports (e.g., basketball) are considerably different than those of Boccia. Therefore, disability severity and sports type may have a cardinal impact on the effect of sports engagement on general mood state.

Within-group analysis revealed a negative moderate ES in POMS-Vigor of the IC group (a decrease in vigor). Decrease in vigor among athletes undergoing intense training may be related to physiological states (e.g., the athletes 


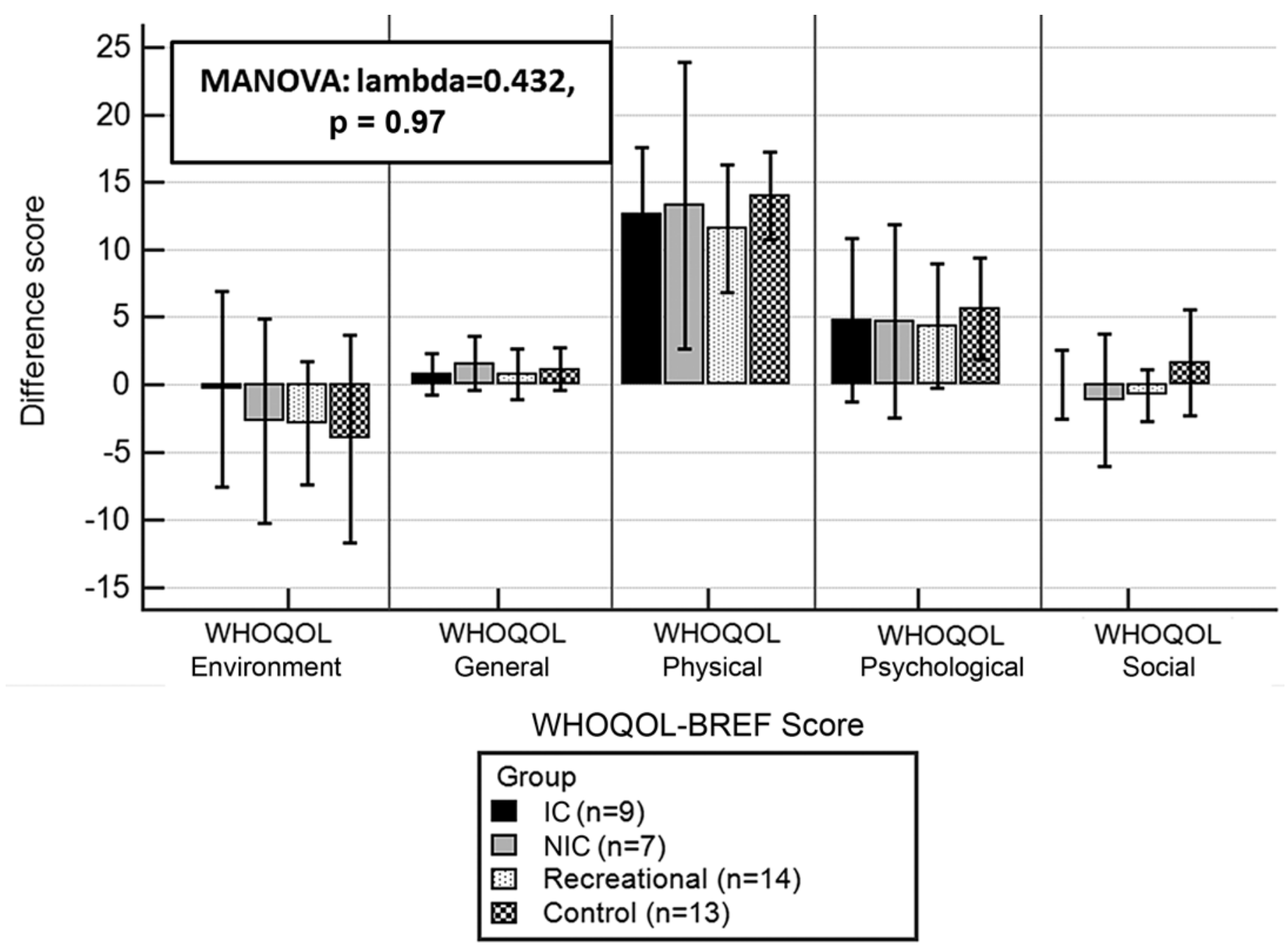

Figure 2.

World Health Organization Quality of Life (WHOQOL)-BREF questionnaire score difference. Mean change was calculated as posttest-pretest. Vertical line extends from the minimum to the maximum value. IC = independent competitive, MANOVA = multivariate analysis of variance, NIC = nonindependent competitive.

are more tired) rather than psychological conditions (e.g., depression) [51]. Therefore, this finding may represent a negative physiological effect.

\section{State-Trait Anxiety Inventory}

In the current study, ESs of Anxiety-State in the IC group and NIC group were considerably larger than the trivial ESs observed in both the recreational and control groups. This finding supports previous findings. For instance, Martin et al. examined differences between the top 12 athletes on the gold medal-winning 2004 U.S. women's Paralympic basketball team and 13 athletes attending the selection camp who did not make the team [31]. The results indicated that athletes who made the Paralympic team scored lower in anxiety.

In summary, the results from the current study extend and corroborate previous findings, which suggest that exercise is associated with lower anxiety levels in athletes with disability and particularly in those who are engaged in more vigorous sport activity.

\section{World Health Organization Quality of Life-BREF}

Physical activity is a modifiable factor that has been associated with quality of life in people with physical 


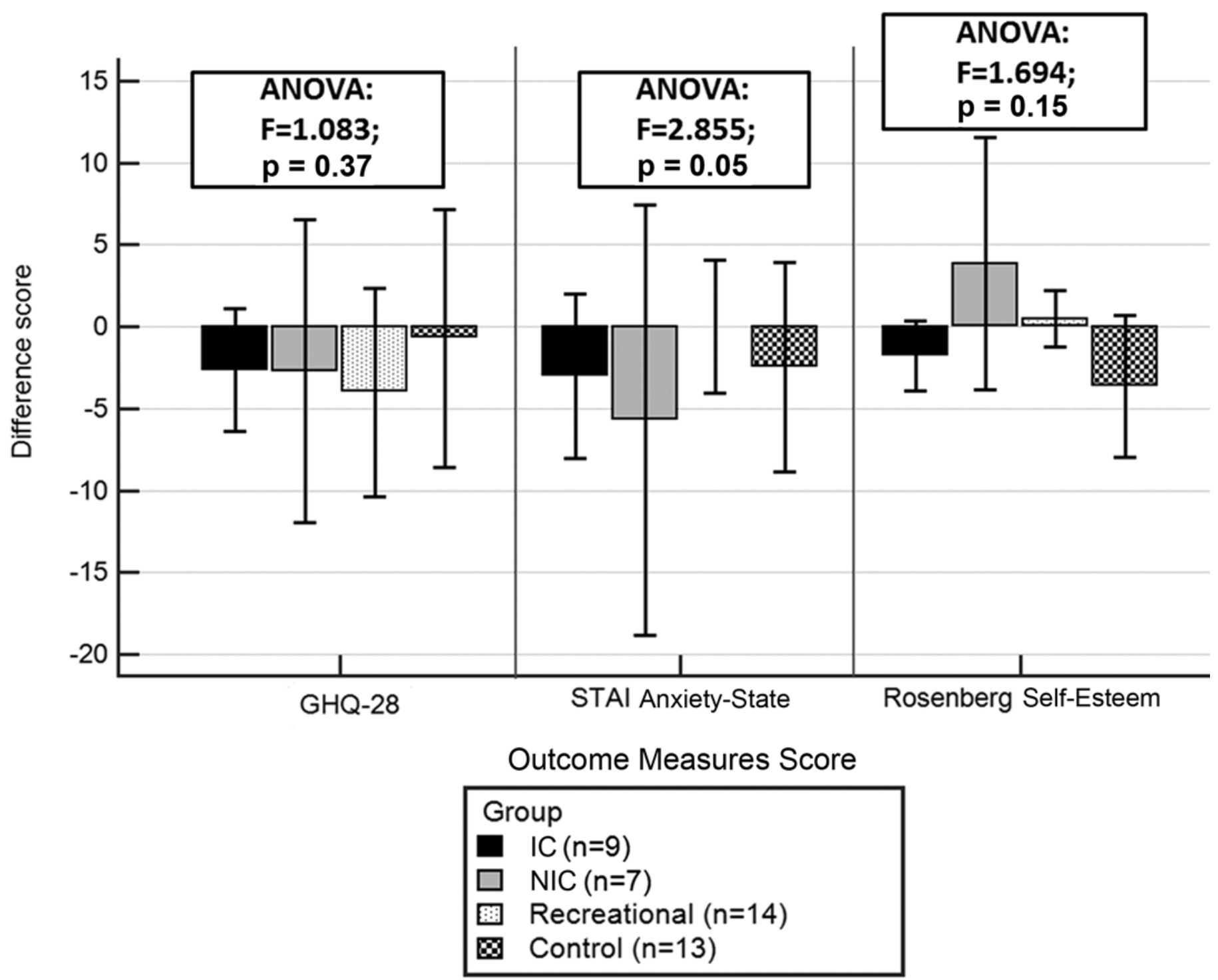

Figure 3.

General Health Questionnaire-28 (GHQ-28), State-Trait Anxiety Inventory (STAI), and Rosenberg Self-Esteem score difference. Mean change was calculated as posttest-pretest. Vertical line extends from the minimum to the maximum value. ANOVA $=$ analysis of variance, $\mathrm{IC}=$ independent competitive, $\mathrm{NIC}=$ nonindependent competitive.

[52-54] and intellectual disabilities [55]. Accordingly, in the current study, the three physically active groups demonstrated a significant increase in physical quality of life and exhibited moderate-to-large ESs in several other quality of life domains. However, the nonactive control group exhibited similar changes in quality of life. The changes observed in the control group may be related to the fact that all study groups received therapy aimed at improving the patient's function. As physical activity involves bodily movement produced by the contraction of skeletal muscles [56], all participants, including the control group, were involved in physical activity. Therefore, the control group may also have experienced a physical activity-associated increase in quality of life.

In all the study's groups, physical quality of life ESs were large. All groups also presented moderate-to-large ESs in psychological quality of life. In contrast, in all study groups, the ESs in environmental and social quality of life 
JRRD, Volume 53, Number 6, 2016

Table 2.

Within-group analysis. Changes from pre- to posttest in psychological parameters. Data presented as mean (standard deviation).

\begin{tabular}{|c|c|c|c|c|c|c|c|c|}
\hline \multirow{2}{*}{ Variable } & \multicolumn{2}{|c|}{ IC $(n=9)$} & \multicolumn{2}{|c|}{ NIC $(n=7)$} & \multicolumn{2}{|c|}{ Recreational $(n=14)$} & \multicolumn{2}{|c|}{ Control $(n=13)$} \\
\hline & Pretest & Posttest & Pretest & Posttest & Pretest & Posttest & Pretest & Posttest \\
\hline \multicolumn{9}{|l|}{$\overline{\text { POMS }}$} \\
\hline Confusion (0-28) & $29.11(3.21)$ & $28.88(8.31)$ & $32.57(9.81)$ & $31.14(9.75)$ & $23.86(12.20)$ & $29.28(5.51)$ & $25.69(10.12)$ & $27.30(10.40)$ \\
\hline Depression $(0-60)$ & $9.22(3.11)$ & $15.55(24.31)$ & $19.28(16.49)$ & $33.14(32.71)$ & $20.00(11.06)$ & $31.57(35.35)$ & $15.46(9.76)$ & $26.30(37.60)$ \\
\hline Fatigue (0-28) & $2.66(1.87)$ & $3.88(3.68)$ & $11.42(6.24)$ & $9.00(7.41)$ & $8.85(5.31)$ & $11.07(7.29)$ & $9.61(6.27)$ & $10.00(9.46)$ \\
\hline Anger $(0-48)$ & $10.11(4.93)$ & $9.22(6.47)$ & $17.28(10.37)$ & $15.14(9.44)$ & $16.14(9.82)$ & $15.78(9.71)$ & $17.69(10.30)$ & $13.46(10.60)$ \\
\hline Total $(0-200)$ & $140.55(10.10)$ & $148.00(34.19)$ & $173.42(47.48)$ & $178.28(46.20)$ & $163.92(35.30)$ & $181.14(51.20)$ & $164.50(37.70)$ & $164.61(61.70)$ \\
\hline \multicolumn{9}{|l|}{ STAI } \\
\hline Anxiety-State & $23.55(5.38)$ & $20.55(7.69)$ & $27.00(10.27)$ & $21.28(5.82)$ & $30.07(4.61)$ & $30.07(7.93)$ & $25.76(10.34)$ & $25.25(10.90)$ \\
\hline Anxiety-Trait & $24.44(8.95)$ & NA & $26.00(10.68)$ & NA & $30.50(5.01)$ & NA & $25.38(10.35)$ & NA \\
\hline \multicolumn{9}{|l|}{ WHOQOL-BREF } \\
\hline Psychological & $16.66(2.54)$ & $21.44(7.65)$ & $16.57(3.25)$ & $21.28(9.28)$ & $15.28(3.96)$ & $19.64(7.23)$ & $11.69(5.60)$ & $17.30(7.36)^{*}$ \\
\hline Social & $12.11(1.53)$ & $12.11(2.93)$ & $12.00(1.91)$ & $10.85(4.77)$ & $9.85(3.7)$ & $9.07(4.26)$ & $9.30(3.17)$ & $10.92(6.61)$ \\
\hline Rosenberg Self-Esteem & $27.77(1.78)$ & $26.00(2.73)$ & $22.42(7.52)$ & $26.85(1.38)^{*}$ & $25.07(1.90)$ & $25.57(2.24)$ & $25.95(2.50)$ & $24.00(3.10)$ \\
\hline GHQ-28 & $10.88(5.44)$ & $8.22(4.14)$ & $14.42(2.07)$ & $11.71(8.75)$ & $15.07(6.76)$ & $11.07(7.55)$ & $15.30(6.53)$ & $14.61(10.64)$ \\
\hline
\end{tabular}

Note: POMS level of significance was set to $p<0.007$ (after Bonferroni adjustment: 0.05/7 = 0.007); STAI, GHQ-28, and Rosenberg Self-Esteem, $p<0.05$; and WHOQOL-BREF, $p<0.01$ (after Bonferroni adjustment: 0.05/5 = 0.01).

${ }^{*}$ Within-group analysis significant differences between pre- and posttest.

GHQ-28 = General Health Questionnaire-28, IC = independent competitive, NA = not applicable, NIC = nonindependent competitive, POMS = Profile of Mood States, STAI $=$ State-Trait Anxiety Inventory, $\mathrm{WHOQOL}=$ World Health Organization Quality of Life.

were trivial to small. The small ESs observed in the latter two domains of quality of life may be accounted for by the nature of these domains' items. The social component of the WHOQOL-BREF consists of items pertaining to personal relationships, sexual activity, and social support. The environmental section focuses on aspects related to factors such as financial resources, physical environment (pollution/noise/traffic/climate), transport, home environment, and health and social care [38]. As social and environmental domains are influenced by external environmental factors, changing physical activity patterns is not sufficient to bring about a change in these quality of life domains. Important change facilitators may consist of altering attitudes toward persons with disabilities and addressing economic and social barriers that limit the ability of persons with disabilities to become full participants in community life [57].

\section{Rosenberg Self-Esteem}

Sport has been reported to be a mediator for selfesteem enhancement among persons with disabilities through challenging their limitations [58]. For instance, in people who have acquired a disability, participation in sport/physical exercise can help them come to terms with their disability and regain self-esteem [59]. Supporting the aforementioned premise, in the current study the control group demonstrated a negative moderate ES (decrease in self-esteem), whereas the NIC group demonstrated a positive moderate ES (an increase in selfesteem). In contrast, participants in the IC group presented negative large ES, indicating a decrease in self-esteem (Table 3). The observed negative ES in selfesteem in the IC group may be attributed to the tendency of athletes to aim for perfectionism in their performance [60], which may be associated with negative responses such as decreased self-esteem [61]. Therefore, in order to better understand the observed changes in the IC group's self-esteem, we need to obtain additional information, such as recent performances in competitions and the coach's overall satisfaction with the athletes' performance. 
Table 3.

Cohen effect size $(d)$ for the mean difference (repeated measures).

\begin{tabular}{|c|c|c|c|c|}
\hline Variable & $\begin{array}{c}\text { IC } \\
(n=9)\end{array}$ & $\begin{array}{c}\text { NIC } \\
(n=7)\end{array}$ & $\begin{array}{c}\text { Recreational } \\
\quad(n=14)\end{array}$ & $\begin{array}{l}\text { Control } \\
(n=13)\end{array}$ \\
\hline \multicolumn{5}{|l|}{$\overline{\text { POMS }}$} \\
\hline Confusion & -0.035 & -0.146 & $0.630^{*}$ & 0.156 \\
\hline Depression & 0.365 & $0.534 *$ & 0.441 & 0.394 \\
\hline Fatigue & 0.417 & -0.354 & 0.347 & 0.047 \\
\hline Anger & -0.154 & -0.216 & -0.036 & -0.404 \\
\hline Tension & -0.307 & $-0.578^{*}$ & -0.190 & -0.236 \\
\hline Vigor & $-0.501 *$ & -0.281 & 0.136 & 0.359 \\
\hline Total & 0.295 & 0.103 & 0.391 & 0.001 \\
\hline \multicolumn{5}{|l|}{ STAI } \\
\hline Anxiety-State & -0.451 & $-0.686^{*}$ & 0.000 & -0.046 \\
\hline Anxiety-Trait & NA & NA & NA & NA \\
\hline \multicolumn{5}{|l|}{ WHOQOL-BREF } \\
\hline Environment & -0.045 & -0.313 & -0.374 & -0.444 \\
\hline General & $0.516^{*}$ & $1.226^{\dagger}$ & 0.354 & $0.517 *$ \\
\hline Physical & $2.923^{\dagger}$ & $1.317^{\dagger}$ & $1.894^{\dagger}$ & $2.814^{\dagger}$ \\
\hline Psychological & $0.837^{\dagger}$ & $0.677^{*}$ & $0.746^{*}$ & $0.858^{\dagger}$ \\
\hline Social & 0.000 & -0.314 & -0.194 & 0.311 \\
\hline GHQ-28 & $-0.551^{*}$ & -0.426 & $-0.557 *$ & -0.078 \\
\hline $\begin{array}{l}\text { Rosenberg Self- } \\
\text { Esteem }\end{array}$ & $-0.768 *$ & $0.713^{*}$ & 0.240 & $-0.679 *$ \\
\hline \multicolumn{5}{|c|}{$\begin{array}{l}\text { Note: Cohen } d \text { is based on a single pooled standard deviation (Cohen } d=\text { mean } \\
\Delta / \text { standard deviation }{ }_{\text {average from two means }} \text { ) and was corrected for dependence } \\
\text { between means using Morris and DeShon equation [50]. } \\
\text { * Moderate differences (Cohen } d=0.51-0.80 \text { ). } \\
\text { 'Large differences (Cohen } d \geq 0.80 \text { ). } \\
\text { GHQ-28 = General Health Questionnaire-28, IC = independent competitive, } \\
\text { NA = not applicable, NIC = nonindependent competitive, POMS = Profile of } \\
\text { Mood States, STAI = State-Trait Anxiety Inventory, WHOQOL = World } \\
\text { Health Organization Quality of Life. }\end{array}$} \\
\hline
\end{tabular}

The Boccia training effect described in this study may be related to specific game requirements. More specifically, Boccia requires not only physical abilities such as accuracy, but also strategic planning, mental toughness, comprehensive learning processes, and social exchange. All these game requirements may provide unique and added value to the psychosocial benefits of participation in this activity. Within other sports for people with severe disability, only one study [12] reported psychosocial benefits. However, this study focused on power soccer players and looked at social gains of practicing with friends.

\section{General Health Questionnaire-28}

Research has shown that by engaging in healthful behaviors, such as exercise, persons with disabilities can increase overall mental well-being [62-65]. The beneficial effect of physical activity on mental well-being is not surprising, as physical activity can promote physical health (e.g., reduce activity limitations). In turn, physical health is considered an important factor affecting mental well-being [66]. Accordingly, in the current study, the three active groups presented small-to-moderate improvements in their mental well-being (Table 3). In contrast, the nonactive control group presented only trivial ESs.

\section{Limitations}

The current study was subjected to several limitations. The generalizability of the results can be questioned owing to the small sample size in each study group. In spite of the lack of power, we described considerable ESs, which may indicate that the changes observed are not trivial. In addition, the reported ESs can be used in future research endeavors, in order to calculate the number of subjects required in order to avoid a type $\beta$ or type II error [67]. In addition, the measurement of the psychosocial factors relied on generic instruments, which might have missed issues pertaining to a participant's specific disability etiology. Finally, it is also important to note that the within-group variability in this study was relatively large. Within-group variation is caused by factors that we cannot or did not control in the study. For instance, the age in the IC, NIC, recreational, and control groups ranged from 25 to $62 \mathrm{yr}, 23$ to $56 \mathrm{yr}, 36$ to $59 \mathrm{yr}$, and 34 to $66 \mathrm{yr}$, respectively. This variability in age may account for part of the within-group variability observed. Therefore, in future studies it may be important to control for confounding variables such as age.

\section{CONCLUSIONS}

In conclusion, few studies have examined the influence of physical activity on the psychosocial status of individuals with severe physical disabilities. Our results indicate that the rehabilitation program had a general positive effect on the psychosocial attributes of participants in the study, regardless of their research group. The variable in which the greatest ES change occurred in all study groups was physical-health-related quality of life. Nevertheless, we did find an added value of the Boccia program. The active groups, especially the IC and NIC groups, demonstrated more favorable changes in psychosocial factors. However, intense training may also yield negative effects, such as an increase in depression and confusion and a decrease in vigor. These negative effects may be related to the fatigue demonstrated in rigorously training participants [21]. 
Therefore, coaches and administrators are encouraged to exercise caution regarding the volume and intensity of throwing when planning their athletes' training. In addition to the specific recommendations for Boccia coaches and administrators, the specific effect of Boccia training (as described in the "Introduction") for participants with severe disabilities compared to other types of sport, including power soccer and individual sports, is encouraging. It is recommended that future studies include follow-up periods to study the potential reversibility of the psychosocial benefits of physical activity, when training discontinues.

\section{ACKNOWLEDGMENTS}

\author{
Author Contributions: \\ Study concept and design: S. Barak, N. Mendoza-Laiz, M. T. Gutiérrez \\ Fuentes, M. Rubiera, Y. Hutzler. \\ Interpretation of data and drafting of manuscript: S. Barak, Y. Hutzler. \\ Critical revision of manuscript for important intellectual content and \\ final approval of published version: S. Barak, N. Mendoza-Laiz, \\ M. T. Gutiérrez Fuentes, M. Rubiera, Y. Hutzler. \\ Financial Disclosures: The authors have declared that no competing \\ interests exist. \\ Funding/Support: The research and the preparation of the article \\ were completed with the financial support of CRE Imserso, Ministry \\ of Health, Social Affairs and Equality, Spain. \\ Institutional Review: This study was approved by the Imserso Institu- \\ tional Review Board, and all participants provided informed consent. \\ Participant Follow-Up: The authors plan to inform study participants \\ of the publication of this study.
}

\section{REFERENCES}

1. Webborn N, Van de Vliet P. Paralympic medicine. Lancet. 2012;380(9836):65-71. [PMID:22770458] http://dx.doi.org/10.1016/S0140-6736(12)60831-9

2. Blinde EM, Taub DE. Personal empowerment through sport and physical fitness activity: Perspectives from male college students with physical and sensory disabilities. J Sport Behav. 1999;22:181-202.

3. Hutzter Y, Bar-Eli M. Psychological benefits of sports for the disabled: A review. Scand J Med Sci Sports. 1993;3: $217-28$.

http://dx.doi.org/10.1111/j.1600-0838.1993.tb00386.x

4. Hutzler Y, Sherrill Y. Disability, physical activity, psychological well-being and empowerment: A life-span perspective. In: Lidor R, Bar-Eli M, editors. Sport psychology: Linking theory and practice. Morgantown (WV): Fitness Information Technology, Inc; 1999. p. 281-300.
5. Campbell E, Jones G. Psychological well-being in wheelchair sport participants and non-participants. Adapt Phys Activ Q. 1994;11:404-15. http://dx.doi.org/10.1123/apaq.11.4.404

6. Gioia MC, Cerasa A, Di Lucente L, Brunelli S, Castellano $\mathrm{V}$, Traballesi M. Psychological impact of sports activity in spinal cord injury patients. Scand J Med Sci Sports. 2006; 16(6):412-16. [PMID:17121643] http://dx.doi.org/10.1111/j.1600-0838.2005.00518.x

7. Giacobbi PR Jr, Stancil M, Hardin B, Bryant L. Physical activity and quality of life experienced by highly active individuals with physical disabilities. Adapt Phys Activ Q. 2008;25(3):189-207. [PMID:18765861] http://dx.doi.org/10.1123/apaq.25.3.189

8. Stevens SL, Caputo JL, Fuller DK, Morgan DW. Physical activity and quality of life in adults with spinal cord injury. J Spinal Cord Med. 2008;31(4):373-78. [PMID:18959354] http://dx.doi.org/10.1080/10790268.2008.11760739

9. Bastos T, Corredeira R, Probst M, Fonseca AM. Elite disability sport coaches' views on sport psychology. Int J Psychol Studies. 2013;6:33-34.

10. Hanrahan SJ. Psychological skills training for competitive wheelchair and amputee athletes. Aust Psychol. 1995; 30(2):96-101. http://dx.doi.org/10.1080/00050069508258911

11. Martin JJ. A personal development model of sport psychology for athletes with disabilities. J Appl Sport Psychol. 1999;11(2):181-93. http://dx.doi.org/10.1080/10413209908404199

12. Barfield JP, Malone LA. Perceived exercise benefits and barriers among power wheelchair soccer players. J Rehabil Res Dev. 2013;50(2):231-38. [PMID:23761004] http://dx.doi.org/10.1682/JRRD.2011.12.0234

13. Jeffress MS. Communication, sport and disability: The case of power soccer. Burlington (VT): Ashgate; 2015.

14. Kumar A, Karmarkar AM, Collins DM, Souza A, Oyster ML, Cooper R, Cooper RA. Pilot study for quantifying driving characteristics during power wheelchair soccer. J Rehabil Res Dev. 2012;49(1):75-82. [PMID:22492339] http://dx.doi.org/10.1682/JRRD.2010.09.0191

15. Cerebral Palsy International Sports and Recreation Association (CPISRA). CPISRA Sports Manual, 10th ed [Internet]; CPISRA; 2011 [cited 2014 October 11]; Available from: http://www.cpisra.org/

16. Avila Romero F, Moreno Hernández FJ. [The perception and neuromuscular activity in individuals with cerebral palsy playing Boccia: Methogological evaluation]. Una propuesta metodológica de evaluación. Apunts: Educación física y deportes. 2000;60:59-65. Spanish.

17. Romero AR, del Campo VL, Reina-Vaillo R. Analysis of kinetic variables applied or classification of Boccia athletes 
of Classes BC1 \& BC2 [master's thesis]. [Elche (Spain)]: Miguel Hernández University; 2010.

18. Dickson MJ, Fuss FK, Wong KG. Benchmarking of boccia balls: Roll distance, accuracy, stiffness, rolling friction, and coefficient of restitution. Sports Technol. 2011;3:131-40. http://dx.doi.org/10.1080/19346182.2010.540474

19. Morriss L, Wittemannóva J. The effect of blocked versus random training schedule on skills performance in experienced athletes with cerebral palsy. Eur J Adapt Phys Activ. 2010;3(2):17-28.

20. Huang PC, Pan PJ, Ou YC, Yu YC, Tsai YS. Motion analysis of throwing Boccia balls in children with cerebral palsy. Res Dev Disabil. 2014;35(2):393-99. [PMID:24334228] http://dx.doi.org/10.1016/j.ridd.2013.11.017

21. Fong DT, Yam KY, Chu VW, Cheung RT, Chan KM. Upper limb muscle fatigue during prolonged Boccia games with underarm throwing technique. Sports Biomech. 2012; 11(4):441-51. [PMID:23259234]

http://dx.doi.org/10.1080/14763141.2012.699977

22. Molik B, Zubala T, Słyk K, Bigas G, Gryglewicz A, Kucharczyk B. Motivation of the disabled to participate in chosen Paralympics events (wheelchair basketball, wheelchair rugby, and boccia). Fizjoterapia. 2010;18:42-51.

23. Mahoney FI, Barthel DW. Functional evaluation: The Barthel Index. Md State Med J. 1965;14:61-65.

[PMID:14258950]

24. McDowell I, Newell C. Measuring health: A guide to rating scales and questionnaires. 2nd ed. New York: Oxford University Press; 1996. p. 63-67.

25. Centers for Disease Control and Prevention (CDC). National Center for Health Statistics. DATA 2010 [Internet database]. Hyattsville (MD): CDC; 2010 [cited 2010 Sep 30]. Available from:

http://wonder.cdc.gov/data2010/focus.htm

26. McNair DM, Droppleman LF, Lorr M. EdITS Manual for the Profile of Mood States. San Diego (CA): EdITS Educational \& Industrial Testing Service; 1992.

27. Cella DF, Jacobsen PB, Orav EJ, Holland JC, Silberfarb PM, Rafla S. A brief POMS measure of distress for cancer patients. J Chronic Dis. 1987;40(10):939-42.

[PMID:3611291]

http://dx.doi.org/10.1016/0021-9681(87)90143-3

28. Horvat M, French R, Henschen K. A comparison of the psychological characteristics of male and female able-bodied and wheelchair athletes. Paraplegia. 1986;24(2):115-22.

[PMID:3714291]

http://dx.doi.org/10.1038/sc.1986.15

29. Mastro J, Canabal MY, French R. Psychological profiles of sighted and unsighted beep baseball players. Res Q. 1988; 59(3):262-64.

30. Muraki S, Tsunawake N, Hiramatsu S, Yamasaki M. The effect of frequency and mode of sports activity on the psy- chological status in tetraplegics and paraplegics. Spinal Cord. 2000;38(5):309-14. [PMID:10822404]

http://dx.doi.org/10.1038/sj.sc.3101002

31. Martin JJ, Malone LA, Hilyer JC. Personality and mood in women's Paralympic basketball champions. J Clin Sport Psychol. 2011;5:197-210.

http://dx.doi.org/10.1123/jcsp.5.3.197

32. Tluczek A, Henriques JB, Brown RL. Support for the reliability and validity of a six-item state anxiety scale derived from the State-Trait Anxiety Inventory. J Nurs Meas. 2009; 17(1):19-28. [PMID:19902657] http://dx.doi.org/10.1891/1061-3749.17.1.19

33. Kaipper MB, Chachamovich E, Hidalgo MP, Torres IL, Caumo W. Evaluation of the structure of Brazilian StateTrait Anxiety Inventory using a Rasch psychometric approach. J Psychosom Res. 2010;68(3):223-33.

[PMID:20159207]

http://dx.doi.org/10.1016/j.jpsychores.2009.09.013

34. Chlan L, Savik K, Weinert C. Development of a shortened state anxiety scale from the Spielberger State-Trait Anxiety Inventory (STAI) for patients receiving mechanical ventilatory support. J Nurs Meas. 2003;11(3):283-93.

[PMID:15633782]

http://dx.doi.org/10.1891/jnum.11.3.283.61269

35. Addolorato G, Ancona C, Capristo E, Graziosetto R, Di Rienzo L, Maurizi M, Gasbarrini G. State and trait anxiety in women affected by allergic and vasomotor rhinitis. J Psychosom Res. 1999;46(3):283-89. [PMID:10193919] http://dx.doi.org/10.1016/S0022-3999(98)00109-3

36. Knight RG, Waal-Manning HJ, Spears GF. Some norms and reliability data for the State-Trait Anxiety Inventory and the Zung Self-Rating Depression scale. Br J Clin Psychol. 1983;22(Pt 4):245-49. [PMID:6640176] http://dx.doi.org/10.1111/j.2044-8260.1983.tb00610.x

37. Julian LJ. Measures of anxiety: State-Trait Anxiety Inventory (STAI), Beck Anxiety Inventory (BAI), and Hospital Anxiety and Depression Scale-Anxiety (HADS-A). Arthritis Care Res (Hoboken). 2011;63(Suppl 11):S467-72. [PMID:22588767] http://dx.doi.org/10.1002/acr.20561

38. World Health Organization (WHO). WHOQOL-BREF: Introduction, administration, scoring and generic version of assessment. Geneva (Switzerland): WHO; 1996.

39. Skevington SM, Lotfy M, O'Connell KA; WHOQOL Group. The World Health Organization's WHOQOLBREF quality of life assessment: Psychometric properties and results of the international field trial. A report from the WHOQOL group. Qual Life Res. 2004;13(2):299-310. [PMID:15085902] http://dx.doi.org/10.1023/B:QURE.0000018486.91360.00

40. Rosenberg M. Society and the adolescent self-image. Princeton (NJ): Princeton University Press; 1965. 
41. Gray-Little B, Williams VS, Hancock TD. An item response theory analysis of the Rosenberg Self-Esteem Scale. Pers Soc Psychol Bull. 1997;23:443-51. http://dx.doi.org/10.1177/0146167297235001

42. McAuley E, Elavsky S, Motl RW, Konopack JF, Hu L, Marquez DX. Physical activity, self-efficacy, and selfesteem: Longitudinal relationships in older adults. J Gerontol B Psychol Sci Soc Sci. 2005;60(5):268-75.

[PMID:16131621] http://dx.doi.org/10.1093/geronb/60.5.P268

43. Goldberg DP. Manual of the General Health Questionnaire. Windsor (UK): NFER Publishing; 1978.

44. Feyer AM, Herbison P, Williamson AM, de Silva I, Mandryk J, Hendrie L, Hely MC. The role of physical and psychological factors in occupational low back pain: A prospective cohort study. Occup Environ Med. 2000;57(2): 116-20. [PMID:10711279] http://dx.doi.org/10.1136/oem.57.2.116

45. Jackson C. The General Health Questionnaire. Occup Med (Chic Ill). 2006;57:79-80. http://dx.doi.org/10.1093/occmed/kql169

46. Jones M, Rona RJ, Hooper R, Wesseley S. The burden of psychological symptoms in UK Armed Forces. Occup Med (Lond). 2006;56(5):322-28. [PMID:16720583] http://dx.doi.org/10.1093/occmed/kq1023

47. Mortazavi SS, Shati M, Ardebili HE, Mohammad K, Beni $\mathrm{RD}$, Keshteli AH. Comparing the effects of group and home-based physical activity on mental health in the elderly. Int J Prev Med. 2013;4(11):1282-89.

[PMID:24404363]

48. Armitage P, Berry G, Matthews JN. Statistical methods in medical research. 4th ed. Oxford (UK): Blackwell Science; 2002.

49. Cohen J. Statistical power analysis for behavioral sciences. Revised edition. New York (NY): Academic Press; 1977.

50. Morris SB, DeShon RP. Combining effect size estimates in meta-analysis with repeated measures and independentgroups designs. Psychol Methods. 2002;7(1):105-25. [PMID:11928886] http://dx.doi.org/10.1037/1082-989X.7.1.105

51. Martin DT, Andersen MB, Gates W. Using Profile of Mood States (POMS) to monitor high-intensity training in cyclists: Group versus case studies. Sport Psychol. 2000; 14:138-56. http://dx.doi.org/10.1123/tsp.14.2.138

52. Compton DM, Eisenman PA, Henderson HL. Exercise and fitness for persons with disabilities. Sports Med. 1989;7(3): 150-62. [PMID:2525270] http://dx.doi.org/10.2165/00007256-198907030-00002

53. Motl RW, McAuley E, Snook EM, Gliottoni RC. Physical activity and quality of life in multiple sclerosis: Intermediary roles of disability, fatigue, mood, pain, self-efficacy and social support. Psychol Health Med. 2009;14(1):111-24.

\section{[PMID:19085318]}

http://dx.doi.org/10.1080/13548500802241902

54. Kawanishi CY, Greguol M. Physical activity, quality of life, and functional autonomy of adults with spinal cord injuries. Adapt Phys Activ Q. 2013;30(4):317-37.

[PMID:24197622]

http://dx.doi.org/10.1123/apaq.30.4.317

55. Carmeli E, Barak S, Mohammed M, Kodesh E. Physical exercises can reduce anxiety and improve quality of life among adults with intellectual disability. Int Sport Med J. 2009; 10(2):77-85.

56. Bouchard C, Shephard RJ. Physical activity, fitness and health: The model and key concepts. In: Bouchard C, Shephard RJ, Stephensv T, editors. Physical activity, fitness, and health: International proceedings and consensus statement. Champaign (IL): Human Kinetics; 1994. p. 77-88.

57. United States Department of Health and Human Services (DHHS). The Surgeon General's call to action to improve the health and wellness of persons with disabilities. Rockville (MD): DHHS Office of the Surgeon General; 2005.

58. Swanson SR, Colwell T, Zhao Y. Motives for participation and importance of social support for athletes with physical disabilities. J Clin Sport Psychol. 2008;2:317-36.

http://dx.doi.org/10.1123/jesp.2.4.317

59. Chawla JC. ABC of sports medicine. Sport for people with disability. BMJ. 1994;308(6942):1500-04.

[PMID:7802770]

http://dx.doi.org/10.1136/bmj.308.6942.1500

60. Gould D. Personal motivation gone awry: Burnout in competitive athletes. Quest. 1996;48:275-89. http://dx.doi.org/10.1080/00336297.1996.10484197

61. Hall HK, Kerr AW, Matthews J. Pre-competitive anxiety in sport: The contribution of achievement goals and perfectionism. J Sport Exerc Psychol. 1998;20:194-217. http://dx.doi.org/10.1123/jsep.20.2.194

62. Janssen TW, van Oers CA, van der Woude LH, Hollander AP. Physical strain in daily life of wheelchair users with spinal cord injuries. Med Sci Sports Exerc. 1994;26(6): 661-70. [PMID:8052104] http://dx.doi.org/10.1249/00005768-199406000-00002

63. Santiago MC, Coyle CP, Kinney WB. Aerobic exercise effect on individuals with physical disabilities. Arch Phys Med Rehabil. 1993;74(11):1192-98. [PMID:8239961]

64. Thomas DC. Primary care for people with disabilities. $\mathrm{Mt}$ Sinai J Med. 1999;66(3):188-91. [PMID:10377550]

65. Department of Health. Choosing activity: A physical activity action plan [Internet]. London (UK): Department of Health; 2005 [cited 2014 Oct 11]; Available from: http://www.physicalactivityplan.org/resources/UK.pdf

66. U.K. Inquiry into Mental Health and Well-being in Later Life. Promoting mental health and well-being in later life [Internet]. London (UK): Age Concern/Mental Health 
Foundation; 2006 [cited 2014 October 11]; Available from: https://www.mentalhealth.org.uk/sites/default/files/promoting_mh_wb_later_life.pdf

67. Sullivan GM, Feinn R. Using effect size-or why the $\mathrm{p}$ value is not enough. J Grad Med Educ. 2012;4(3):279-82. [PMID:23997866] http://dx.doi.org/10.4300/JGME-D-12-00156.1

Submitted for publication August 18, 2015. Accepted in revised form April 14, 2016.
This article and any supplementary material should be cited as follows:

Barak S, Mendoza-Laiz N, Gutiérrez Fuentes MT, Rubiera M, Hutzler Y. Psychosocial effects of competitive Boccia program in persons with severe chronic disability. J Rehabil Res Dev. 2016;53(6):973-88. http://dx.doi.org/10.1682/JRRD.2015.08.0156

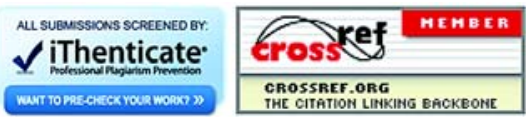


